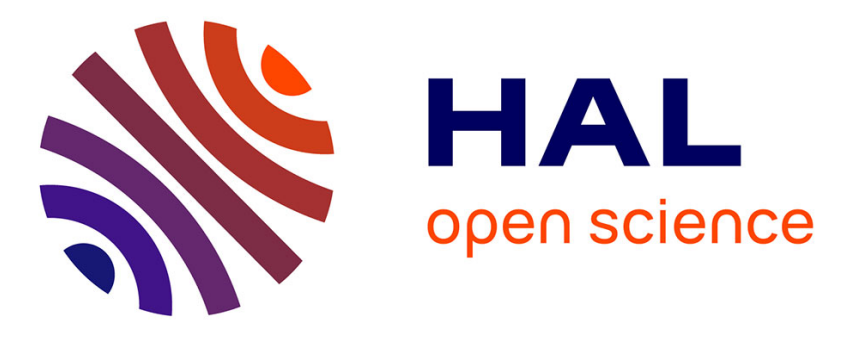

\title{
A Scheduling Tool for Achieving Zero Defect Manufacturing (ZDM): A Conceptual Framework
}

Foivos Psarommatis, Dimitris Kiritsis

\section{To cite this version:}

Foivos Psarommatis, Dimitris Kiritsis. A Scheduling Tool for Achieving Zero Defect Manufacturing (ZDM): A Conceptual Framework. IFIP International Conference on Advances in Production Management Systems (APMS), Aug 2018, Seoul, South Korea. pp.271-278, 10.1007/978-3-319-99707-0_34 . hal-02177861

\section{HAL Id: hal-02177861 \\ https://hal.inria.fr/hal-02177861}

Submitted on 9 Jul 2019

HAL is a multi-disciplinary open access archive for the deposit and dissemination of scientific research documents, whether they are published or not. The documents may come from teaching and research institutions in France or abroad, or from public or private research centers.
L'archive ouverte pluridisciplinaire HAL, est destinée au dépôt et à la diffusion de documents scientifiques de niveau recherche, publiés ou non, émanant des établissements d'enseignement et de recherche français ou étrangers, des laboratoires publics ou privés.

\section{(c)(1)}

Distributed under a Creative Commons Attribution| 4.0 International License 


\title{
A Scheduling tool for achieving Zero Defect Manufacturing (ZDM): a conceptual framework
}

\author{
Foivos Psarommatis* and Dimitris Kiritsis \\ École polytechnique fédérale de Lausanne, ICT for Sustainable Manufacturing, EPFL SCI-STI- \\ DK, Lausanne, Switzerland \\ foivos.psarommatisepfl.ch
}

\begin{abstract}
Contemporary manufacturing landscape has changed and has become highly volatile and demanding. Product Life Cycle has significantly decreased because of the consumers' need for personalized products in shorter period of time. This need forced the manufacturers to produce smaller batches of highly diversified products instead of producing huge batches of the same product. These newly imposed production requirements made the manufacturers struggle to optimize their productions in such short period of time and therefore, these production requirements created the need for more efficient, productive and ecofriendly planning and scheduling. The solution to this problem can be given partially by a concept named "Zero Defect Manufacturing" (ZDM). The goal of ZDM is to eliminate defected parts and therefore achieving higher efficiency, eco-friendliness and lower production costs. There are four ZDM strategies that are interconnected with each other: detection, repair, prediction and prevention. The current research work focuses on the Beginning of Life of the product and considers the development of a dynamic Scheduling tool combined with an intelligent Decision Support System (DSS) that takes into consideration the ZDM strategies for eliminating defected parts during production. The elimination of defected parts would be done mainly by creating specific algorithms for predicting when a defect may occur and for taking the right decisions in order to prevent the defect occurrence. Finally, an industrial example is presented in order to illustrate the potential benefits of such an approach.
\end{abstract}

Keywords: Zero Defect Manufacturing, Defect prediction, Scheduling.

\section{Introduction \& State of the Art}

Nowadays, manufacturing environment is highly volatile and rapidly changing. Also the need of products is increasing exponentially, and therefore Product Life Cycle is shortened [1]. As a result, more products are required to be manufactured or remanufactured [2]. So far, manufacturers used to produce large batches of the same product, but these new market requirements forced them to produce small batches of different products. This production strategy created a problem to the manufacturers that they have never faced in the past. Manufacturers are producing so many different products leaving no room for production optimization, as it was happening so far. The result of 
this situation is high number of defected parts which are discarded, recycled or they are repaired if it is possible [3]. This approach increases the cost of the final product and the energy consumption, which may turn the production process non-profitable.

Global competition is very tough, therefore manufacturers must be able to provide innovative and intricate products of high quality, with less process iterations, and more cost competitiveness, if they want to survive. The existing manufacturing systems cannot completely satisfy these requirements because of their deterministic approach to decision-making in an uncertain environment [4].

\subsection{Zero Defect Manufacturing concept}

Zero Defect Manufacturing (ZDM) is a concept in quality management introduced in the 1960s by the US Army department. It has now become common practice which aims at reducing the number of errors and defects made during the manufacturing process of a product and therefore, make the production process more cost efficient, more eco-friendly and competitive. ZDM refers to a state where waste is completely eliminated from the manufacturing process and where defects are reduced to the minimum [5]. The concept of ZDM consists of four main elements: detecting, repairing, predicting, preventing, and their interconnections can be seen in Fig. 1. Even though zero defects are not possible to achieve in practice, the quest relies on perfection in order to improve general quality of products and processes. Waste, defined as all the tools and processes that are unproductive and that do not create value or add cost to the final product or service, is meant to disappear.

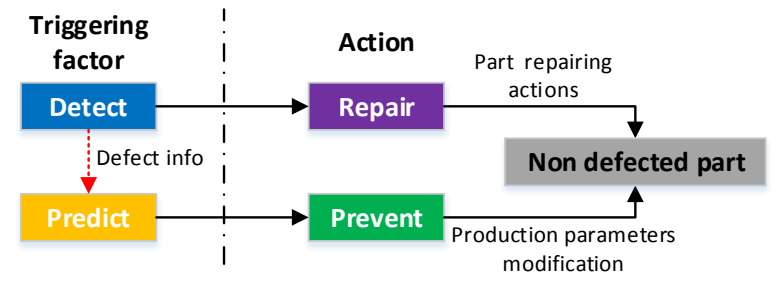

Fig. 1. Zero Defect Manufacturing elements

Many studies already worked on the way to achieve ZDM. In their study, Ferretti et al., (2013) [1] described a first classification of actions that can be implemented in all kind of manufacturing processes in order to reach the goal of a production with a low percentage of scrap pieces. They introduce two main categories of actions: a) indirect actions, which are related to maintenance operations, training operators and raw material inspections, mainly and b) the direct actions are directly performed on the manufacturing process itself, with two main possibilities, in-process or post-process actions.

ZDM is a very promising concept, but still there is no complete solution for the manufacturers. Most of the ZDM applications focus on optimizing processes on machine level and not to a higher level such us the scheduling level. Real-time events can disrupt the production, thus the scheduling tools are responsible for keeping production up to a certain level of efficiency. 


\subsection{Production Scheduling}

Production scheduling is a very important and challenging problem in many manufacturing and process industries [6]. As information technology evolves, it allows to use real-time data in order to use them to solve dynamic, stochastic environment, complex manufacturing scheduling problems [7].

Dios \& Framinan (2016) [8] investigated 99 computer based scheduling tools and their findings were very interesting, $41 / 99$ tools were considering the objective of due dates fulfilment. Further to that other objectives commonly used are feasibility, resource usage, set up time reduction, make span and cycle time. On the other hand only $5 / 99$ where considering the product quality [8], which is the primary case of ZDM. However, few papers take both manufacturing system scheduling and workforce scheduling into consideration [9].

Production systems operating in a highly dynamic environment where unpredictable events may occur and make the current schedule unfeasible [7]. Literature on dynamic scheduling has classified real-time events into two categories: a) Resource - related and b) Job - related [10]. This is mentioned because for applying ZDM a new category of real time events should be introduced and this is "product related" real time events.

\section{Framework Architecture \& Functionalities}

Up to now, most of the approaches in management and maintenance of production systems were "Machine oriented", but this has some limitations due to the fact that the outcome of a production system is a product. Therefore, in the context of the current work, a "Product oriented" approach is proposed and aligned with ZDM concept. Fig. 2 illustrates the concept that it is proposed in order to address and reduce the product defects during production as it is imposed by ZDM.

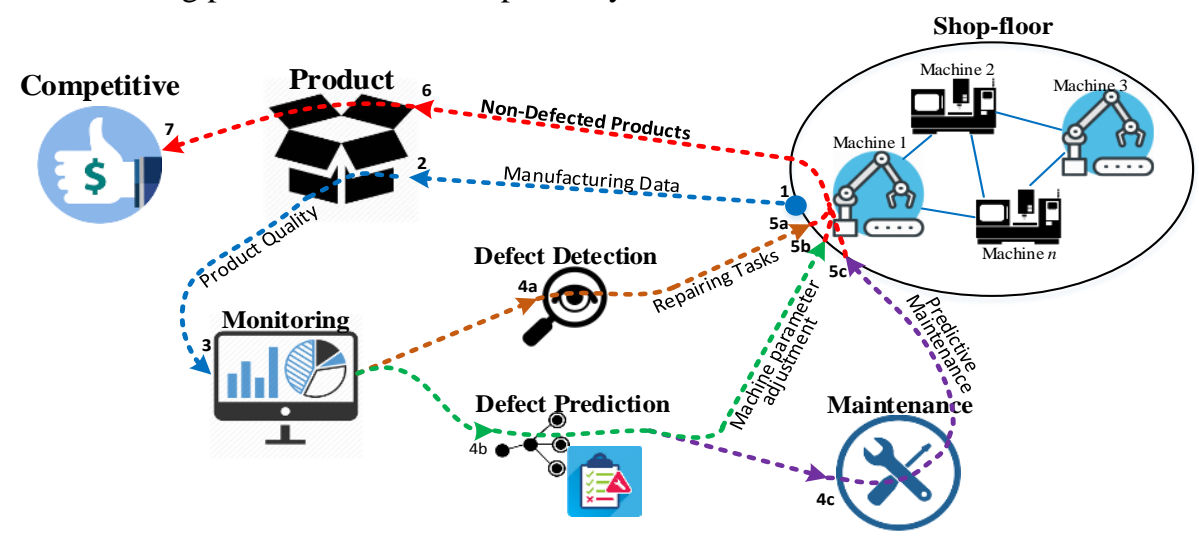

Fig. 2. Product oriented ZDM

The abovementioned concept can be implemented by integrating a DSS tool that complies with the ZDM objectives and mainly the "prediction" and "prevention" of a defect, into a dynamic scheduling tool. 
The purpose is to provide a tool that will be capable to manage production with a more efficient way and able to cope with the contemporary production and market requirements. The difference with the current scheduling tools would be that instead for the scheduling tool to be "machine" oriented it would be "product" oriented and respond primarily to "product" related real time events, besides the other two categories.

Fig. 3 illustrates the conceptual framework of the proposed tool with the informational flow among the scheduling tool, the DSS and the shop floor. The DSS will utilize real-time data from the shop floor in order to predict or detect a defect, then the outcome of the DSS is fed into the scheduling tool and the scheduling tool updates the schedule according to the suggestions that the DSS produced.

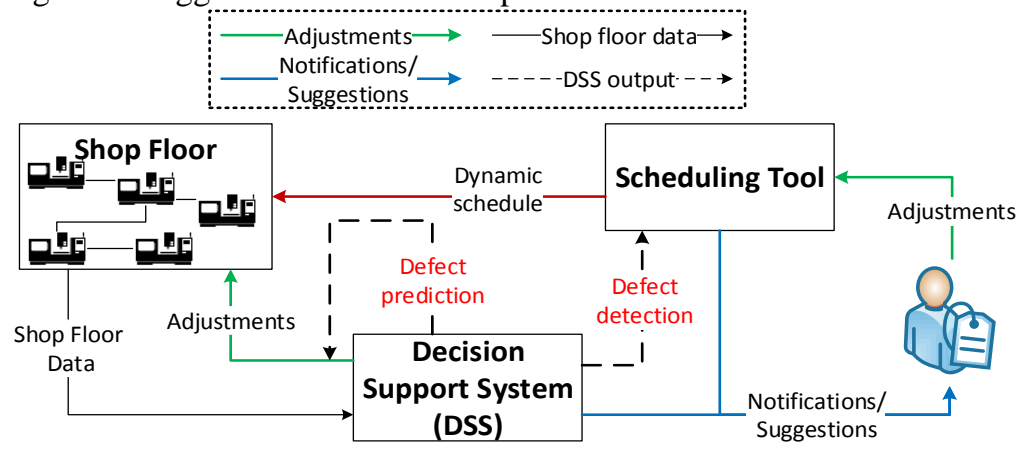

Fig. 3. Overall framework of the proposed tool

\subsection{Decision Support System (DSS)}

The DSS tool will consist of three individual components: a) the defect detection module, b) the defect prediction module and c) decision making algorithms for suggesting a solution based on user-defined rules. Special attention needs to be given to both the defect prediction and the decision-making algorithms. The defect prediction module is a crucial part of the whole tool, because it is more efficient to prevent a defect before it happens. The figure below (Fig. 4) depicts the overall work flow of the defect prediction module.

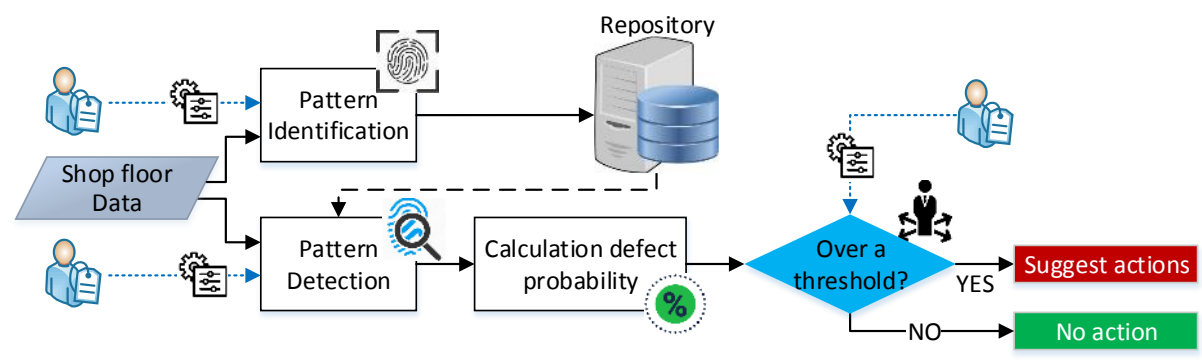

Fig. 4. Defect prediction overall work flow

This module will use real time data from the shop floor (product dimensional measurements, sensorial data, machine data etc.). Then based on specific "rule based" designed 
algorithms will analyze, identify and detect patterns, using user-adjusted parameters in order to fit to each individual use case. When a pattern is detected, up to a certain percentage (user defined), this percentage is fed on the decision-making algorithms in order to suggest solution for preventing the defect to occur. The final component is the defect detection, which by using the collected shop floor data will be able to detect defect and then the DSS will produce the required repairing tasks if it is repairable, and forward these tasks to the scheduling tool in order to re-schedule the production.

\subsection{Scheduling tool}

When real time events, that disrupt the production, are happening the output of the DSS is fed into the dynamic scheduling tool along with the shop floor status and specification. The new schedule is produced according a specific set of user defined criteria. When the new schedule is produced, the Key Performance Indicators (KPIs) are calculated and if they are acceptable the updated schedule is released, otherwise the schedule is re-calculated with different criteria weights until KPIs are acceptable.

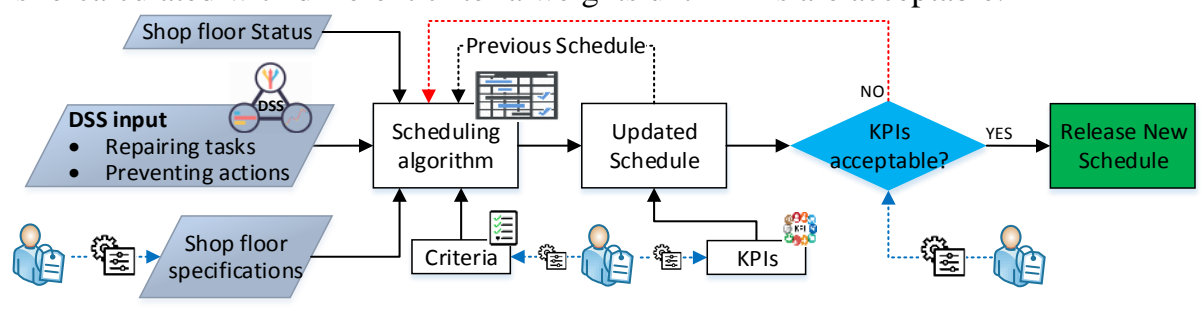

Fig. 5. Scheduling tool overall work flow

The primary criterion that the scheduling tool will consider for the production of the schedule is the product quality and afterwards all the other criteria and KPIs that each manufacturer has chosen. This is critical for the incorporation of ZDM concept to the scheduling tool. Also the novelty of the approach described above is the fact that the system will be tuned and operated based on "product" oriented events rather than "machine" oriented events which are dominantly used in such tools.

\section{$3 \quad$ Industrial application}

The presented framework will be tested through two real life industrial use cases from a semiconductor and a hard metal manufacturer. The testing will be performed in three stages. At the beginning, the two individual components the Scheduling tool and the DSS tool will be tested and validated and at the final stage the integration of the two components will be tested and validated as well.

In order to illustrate the benefits of the proposed approach, a small example has been prepared in this scope utilizing data coming from the semiconductor manufacturer. The example considers three workstations (WS) for producing one type of product (P1). The WS1 and WS2 are manufacturing the two out of three components that $\mathrm{P} 1$ requires, component 1 and component 2 respectively $(\mathrm{C} 1$ and $\mathrm{C} 2$ ). $\mathrm{P} 1$ besides $\mathrm{C} 1$ and $\mathrm{C} 2$ requires 
also $\mathrm{C} 3$, which is an outsourced component. Afterwards, all the components going to the ws 3 in order to be assembled. WS1 has defect ratio $2.3 \%$, WS 2 has $2.9 \%$ and WS3 has $4.1 \%$. All the calculations will be done for an order of 100 parts, each's part materials cost 70 money units (MU) and requires $9.6 \mathrm{~min}$ to be produced. Further to that if, a defect occurs at ws 1 or ws 2 has $35 \%$ and $25 \%$ probability of being repaired whereas if a defect occurs in ws 3 the assembled part cannot be repaired. The graph below (Fig. 6) illustrates the results from this example for four strategies production with repairing the defects (S1), without repairing the defects (S2), applying a defect prediction and repair the defected parts (S3) and finally applying defect prediction without repairing the defected parts (S4). All these strategies are compared with each other and with the normal production without defects. As it was expected the highest cost and latest order completion time is for S2. The S3 and S4 where considering a defect prediction probability of $60 \%$. The outcome of this example in terms of cost is that S3 and S4 behave only $2.56 \%$ and $3.46 \%$, respectively, worse than the ideal conditions whereas S1 and S2 have $6.16 \%$ and $8.21 \%$ respectively. The order completion time follows similar trend as the production cost. S3 and S4 are considering the proposed approach and shows better behavior than the S1 and S2 with $3.69 \%$ and $4.93 \%$ respectively.

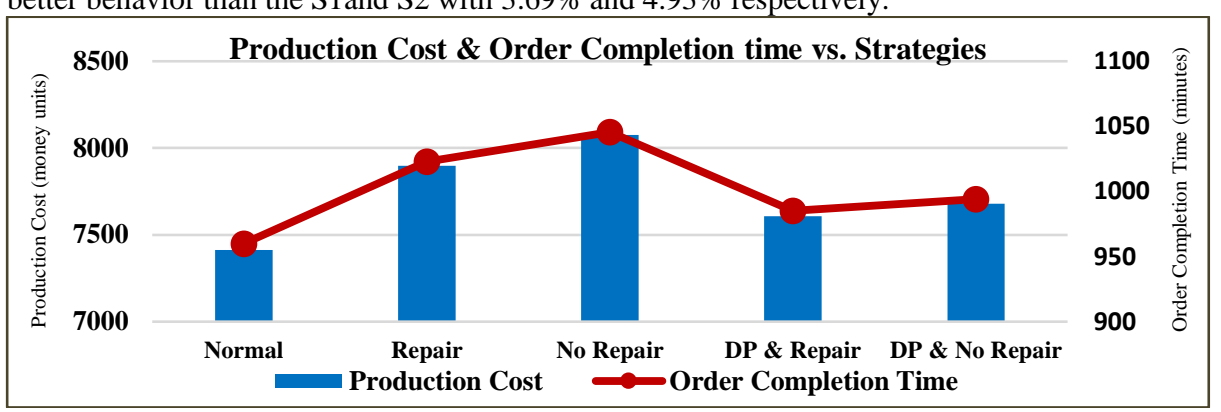

Fig. 6. Results from example case

\section{Conclusions}

The scheduling of a manufacturing system is a very important and critical problem and manufacturers face it every day. These days manufacturers are struggling to keep their productions up to a certain level of efficiency. This is because instead of producing large batches of the same product they produce smaller batches of multiple products. This situation leaves no time to manufacturers to optimize their production for a specific product. Driven by this need the current research work is proposed. There are numerous scheduling tools available in the literature but all of them are "machine" oriented, something that is not acceptable in the ZDM strategy. ZDM concept has as principle that everything are "product" oriented. Therefore, the proposed scheduling tool will be "product" oriented. Further to that, the integrated DSS besides the decisionmaking will have functionality to be able to predict when a defect will occur and therefore prevent it minimizing the production costs. The outcome of the current proposal would be to give to the manufactures a tool that will allow them to cope with the production of small batches of highly versatile products and at the same time keeping high quality standards. Furthermore, the results from the industrial example showed that 
there is a potential in such an approach especially in cases that the repair of a component is not feasible. Finally, this approach has some limitations in terms of the amount of data that are required in order to deliver the expected outcome.

\section{Acknowledgments}

The work presented in this paper is partially supported by the project Z-Factor which is funded by the European Union's Horizon 2020 program under grant agreement No 723906.

\section{References}

1. Ferretti, S., Caputo, D., Penza, M., D’Addona, D.M.: Monitoring systems for zero defect manufacturing. Procedia CIRP. 12, 258-263 (2013).

2. Zhou, L., Gupta, S.M., Kinoshita, Y., Yamada, T.: Pricing Decision Models for Remanufactured Short-Life Cycle Technology Products with Generation Consideration. Procedia CIRP. 61, 195-200 (2017).

3. Colledani, M., Coupek, D., Verl, A., Aichele, J., Yemane, A.: Design and evaluation of inline product repair strategies for defect reduction in the production of electric drives. Procedia CIRP. 21, 159-164 (2014).

4. Manupati, V.K., Putnik, G.D., Tiwari, M.K., Ávila, P., Cruz-Cunha, M.M.: Integration of process planning and scheduling using mobile-agent based approach in a networked manufacturing environment. Comput. Ind. Eng. 94, 63-73 (2016).

5. Myklebust, O.: Zero defect manufacturing: A product and plant oriented lifecycle approach. Procedia CIRP. 12, 246-251 (2013).

6. Ferris, M.C., Maravelias, C.T., Sundaramoorthy, A.: Simultaneous batching and scheduling using dynamic decomposition on a grid. INFORMS J. Comput. 21, 398-410 (2009).

7. Ouelhadj, D., Petrovic, S.: A survey of dynamic scheduling in manufacturing systems. J. Sched. 12, 417-431 (2009).

8. Dios, M., Framinan, J.M.: A review and classification of computer-based manufacturing scheduling tools. Comput. Ind. Eng. 99, 229-249 (2016).

9. Qu, S., Wang, J., Govil, S., Leckie, J.O.: Optimized Adaptive Scheduling of a Manufacturing Process System with Multi-skill Workforce and Multiple Machine Types: An Ontology-based, Multi-agent Reinforcement Learning Approach. Procedia CIRP. 57, 55-60 (2016).

10.Vieira, G.E., Herrmann, J.W., Lin, E.: Analytical models to predict the performance of a single-machine system under periodic and event-driven rescheduling strategies. Int. J. Prod. Res. 38, 1899-1915 (2000). 